\title{
Identification of genomic regions associated with feed efficiency in Nelore cattle
}

\author{
Priscila SN de Oliveira ${ }^{1}$, Aline SM Cesar², Michele L do Nascimento², Amália S Chaves², Polyana C Tizioto ${ }^{1}$, \\ Rymer R Tullio ${ }^{3}$, Dante PD Lanna ${ }^{2}$, Antonio N Rosa ${ }^{4}$, Tad S Sonstegard ${ }^{5}$, Gerson B Mourao ${ }^{2}$, James M Reecy ${ }^{6}$, \\ Dorian J Garrick ${ }^{6}$, Maurício A Mudadu ${ }^{3}$, Luiz L Coutinho ${ }^{2}$ and Luciana CA Regitano ${ }^{3^{*}}$
}

\begin{abstract}
Background: Feed efficiency is jointly determined by productivity and feed requirements, both of which are economically relevant traits in beef cattle production systems. The objective of this study was to identify genes/ QTLs associated with components of feed efficiency in Nelore cattle using Illumina BovineHD BeadChip (770 k SNP) genotypes from 593 Nelore steers. The traits analyzed included: average daily gain (ADG), dry matter intake (DMI), feed-conversion ratio (FCR), feed efficiency (FE), residual feed intake (RFI), maintenance efficiency (ME), efficiency of gain (EG), partial efficiency of growth (PEG) and relative growth rate (RGR). The Bayes $B$ analysis was completed with Gensel software parameterized to fit fewer markers than animals. Genomic windows containing all the SNP loci in each $1 \mathrm{Mb}$ that accounted for more than $1.0 \%$ of genetic variance were considered as QTL region. Candidate genes within windows that explained more than $1 \%$ of genetic variance were selected by putative function based on DAVID and Gene Ontology.

Results: Thirty-six QTL (1-Mb SNP window) were identified on chromosomes 1, 2, 3, 5, 6, 7, 8, 9, 10, 12, 14, 15, 16, $18,19,20,21,22,24,25$ and 26 (UMD 3.1). The amount of genetic variance explained by individual QTL windows for feed efficiency traits ranged from $0.5 \%$ to $9.07 \%$. Some of these QTL minimally overlapped with previously reported feed efficiency QTL for Bos taurus. The QTL regions described in this study harbor genes with biological functions related to metabolic processes, lipid and protein metabolism, generation of energy and growth. Among the positional candidate genes selected for feed efficiency are: HRH4, ALDHTA1, APOA2, LINTC, CXADR, ADAM12 and MAP7.
\end{abstract}

Conclusions: Some genomic regions and some positional candidate genes reported in this study have not been previously reported for feed efficiency traits in Bos indicus. Comparison with published results indicates that different QTLs and genes may be involved in the control of feed efficiency traits in this Nelore cattle population, as compared to Bos taurus cattle.

Keywords: Bos indicus, Candidate gene, Residual feed intake, Single nucleotide polymorphisms

\section{Background}

Feed efficiency has a major influence on the unit cost of beef production. Selection of efficient animals not only improves the producer's profitability, but can lead to significant reductions in the required pasture area per unit of production, decrease feed cost in feedlots, as well as, reduced environmental impact, through lower carbon and methane emissions [1].

\footnotetext{
* Correspondence: luciana.regitano@embrapa.br

${ }^{3}$ Embrapa Southeast-Cattle Research Center, 13560-970 Sao Carlos, SP, Brazil

Full list of author information is available at the end of the article
}

Feed efficiency is typically defined as feed conversion ratio (DMI; dry matter intake divided by ADG; average daily gain), nonetheless other indexes have been studied, such as residual feed intake (RFI; [2]), maintenance efficiency (ME; [3]), partial efficiency of growth (PEG; [4]), efficiency of gain (EG) and relative growth rate (RGR; [5]). Despite its moderate heritability from 0.20 to 0.30 [6-9], feed efficiency has not been considered in Brazilian breeding programs, probably due to the difficulties associated with collection of individual feed intake data [6].

\section{() Biomed Central}

(c) 2014 de Oliveira et al.; licensee BioMed Central Ltd. This is an Open Access article distributed under the terms of the Creative Commons Attribution License (http://creativecommons.org/licenses/by/2.0), which permits unrestricted use, distribution, and reproduction in any medium, provided the original work is properly credited. The Creative Commons Public Domain Dedication waiver (http://creativecommons.org/publicdomain/zero/1.0/) applies to the data made available in this article, unless otherwise stated. 
Brazil is one of the world's leading beef producers and exporters, and the Bos indicus Nelore is the predominant cattle breed in Brazil. Bos indicus animals are known for their adaptability and resilience in tropical environments. Nevertheless, there are only a few [10] genomic studies reported for feed efficiency traits in this breed.

Genome wide association studies (GWAS) involve whole genome search for chromosomal regions that are significantly associated with phenotype, and can be used for QTL detection, determination of gene networks or genomic selection [11,12]. The detection of genomic regions and candidate genes which influence feed efficiency traits in Nelore should contribute to breeding programs. The objective of this study was to identify genes/QTLs associated with feed efficiency traits in Nelore by genome wide association study using the BovineHD BeadChip (770 k) and Bayesian statistical approaches.

\section{Results and discussion Phenotypic data}

The mean values for all traits evaluated in this study (Table 1) are in agreement with the literature [13-17].

\section{Genome wide association study}

Table 2 shows mean genetic and residual variances and genomic heritability, the proportion of phenotypic variance explained by markers using Bayes B, which assumes that SNP effects have a locus-specific variance and some fraction of markers $(\pi)$ have no effect $[18,19]$.

The estimated proportion of phenotypic variance explained by genome markers or "genomic heritability" for all measures of feed efficiency were moderate to high, except for RGR (Table 2). Estimated moderate heritability for feed efficiency traits are in agreement with published estimates from traditional and genomic analyses $[6,8,9,20,21]$.

The amount of genetic variance explained by individual QTL windows for feed efficiency traits ranged from $0.5 \%$ to $9.07 \%$ (Table 3, Additional file 1: Table S1).

Table 1 Descriptive statistics for feed efficiency traits in Nelore cattle

\begin{tabular}{lll}
\hline Phenotype & N & Mean \pm SE \\
\hline ADG [Average Daily Gain; kg/d] & 593 & $1.274 \pm 0.34$ \\
DMI [Dry Matter Intake; kg/d] & 591 & $8.451 \pm 1.28$ \\
FCR [Feed Conversion Ratio; kg/kg] & 516 & $7.147 \pm 3.07$ \\
FE [Feed Efficiency, kg/kg] & 516 & $0.155 \pm 0.04$ \\
RFI [Residual Feed Intake, kg/d] & 591 & $0.001 \pm 0.62$ \\
ME [Maintenance Efficiency; kg/kg] & 376 & $0.349 \pm 0.13$ \\
EG [Efficiency of Gain, kg/Mcal] & 376 & $0.207 \pm 0.10$ \\
PEG [Partial Efficiency of Growth] & 375 & $0.275 \pm 0.05$ \\
RGR [Relative Growth Rate; \%/d] & 593 & $0.165 \pm 0.04$ \\
\hline
\end{tabular}

Table 2 Posterior means of variance components for feed efficiency traits in Nelore cattle

\begin{tabular}{lllll}
\hline Phenotype & $\begin{array}{l}\text { Genetic } \\
\text { variance }\end{array}$ & $\begin{array}{l}\text { Residual } \\
\text { variance }\end{array}$ & $\begin{array}{l}\text { Total } \\
\text { variance }\end{array}$ & $\begin{array}{l}\text { Proportion of variance } \\
\text { explained by SNP }\end{array}$ \\
\hline ADG & 0.06 & 0.08 & 0.15 & 0.42 \\
DMI & 0.52 & 1.22 & 1.75 & 0.29 \\
FCR & 2.96 & 4.53 & 7.50 & 0.39 \\
FE & 0.13 & 0.009 & 0.23 & 0.47 \\
RFI & 0.14 & 0.27 & 0.41 & 0.33 \\
ME & 0.01 & 0.01 & 0.02 & 0.51 \\
EG & 0.0042 & 0.0034 & 0.0076 & 0.55 \\
PEG & 0.0027 & 0.0020 & 0.0048 & 0.57 \\
RGR & 0.0024 & 0.0005 & 0.00030 & 0.18
\end{tabular}

ADG: average daily gain [kg/d], DMl: dry matter intake [kg/d], FCR: feed conversion ratio $[\mathrm{kg} / \mathrm{kg}]$, FE: feed efficiency $[\mathrm{kg} / \mathrm{kg}]$, RFI: residual feed intake [kg/d], ME: maintenance efficiency [kg/kg], EG: efficiency of gain [kg/Mcal], PEG: partial efficiency of growth, RGR: relative growth rate $[\% / d]$.

These findings are in agreement to reported results for Bos taurus cattle where SNPs explained large amounts of variation in feed efficiency-related traits [22]. The largest QTLs were located on BTA2, 9 and 12 (Table 3).

Pooling results across all traits, 36 genomic regions (1$\mathrm{Mb}$ windows) that explain $\geq 1 \%$ of genetic variance (Table 3 ) were identified in this study. These were on chromosomes: $1,2,3,5,6,7,8,9,10,12,14,15,16,18,19,20,21,22,24$, 25 and 26. Some of these QTL minimally overlapped with previously reported feed efficiency QTL for other breeds according to QTL database (http://www.animalgenome. org/cgi-bin/QTLdb/BT/index). This outcome may indicate that different QTL may control feed efficiency traits in this Nelore population as compared to Bos Taurus [22-25]. Genomic regions that explained $>0.5 \%$ of genetic variance for all traits are showed in Additional file; and Additional files 2, 3, 4, 5, 6, 7, 8, 9 and 10 show Manhattan plots of proportion of genetic variance explained across the 29 autosome chromosomes for DMI, ADG, FC, FE, RFI, ME, PEG, GE and RGR, respectively.

Three genomic regions explained $>1 \%$ of genetic variance for DMI (Table 3). The region on BTA24 at $32 \mathrm{Mb}$ was also associated with RFI (Additional file 1: Table S1). Two positional and functional candidate genes were selected in this region. Histamine receptor $\mathrm{H} 4(\mathrm{HRH} 4)$ is the first candidate, which is associated with regulation of appetite and immune and inflammatory responses [26]. Histamine is produced by the decarboxylation of histidine by histidine decarboxylase, and it exerts its action by binding to specific histamine receptors (HRs) [27]. Histamine mediates a variety of physiological processes, which includes inflammation and immunity, gastric acid secretion, smooth muscle contraction, tissue growth and repair, food allergies and regulation of appetite and metabolism in humans [28]. The second candidate gene is zinc finger protein 521 (ZNF521) also found as "zinc finger" protein 
Table 3 QTL regions associated with feed efficiency traits in Nelore cattle

\begin{tabular}{|c|c|c|c|c|c|c|}
\hline Phenotype & $\begin{array}{l}\text { SNP window } \\
\text { [start and end SNP] }\end{array}$ & $\begin{array}{l}\text { Number SNP } \\
\text { in window }\end{array}$ & $\begin{array}{l}\% \text { Variance explained } \\
\text { by SNP window }\end{array}$ & Chr & $\begin{array}{l}\text { Map position } \\
\text { [UMD } 3.1 \text { bovine assembly] }\end{array}$ & $\begin{array}{l}\text { Functional } \\
\text { candidate genes }\end{array}$ \\
\hline \multirow[t]{6}{*}{$\overline{A D G}$} & rs133645581-rs137479730 & 231 & 4.94 & 9 & $22019753 \ldots 22993318$ & - \\
\hline & rs134217291- rs43586239 & 245 & 2.91 & 1 & $156005880 \ldots 156999077$ & - \\
\hline & rs134861070-rs133661192 & 176 & 2.33 & 16 & $31007509 \ldots 319986663$ & - \\
\hline & rs109785180- rs42314597 & 181 & 1.62 & 7 & $28006905 \ldots 28999205$ & MARCH3, ALDH7A1 \\
\hline & rs110427506-rs109577271 & 215 & 1.31 & 3 & $8007708 \ldots 8998553$ & $A P O A 2_{21}$ USP 21, UFC1 \\
\hline & rs135933205-rs136131764 & 270 & 1.01 & 14 & $6007610 \ldots 6998560$ & - \\
\hline \multirow[t]{3}{*}{$\mathrm{DMl}$} & rs133031353-rs42739324 & 237 & 3.76 & 24 & $32007830 \ldots 32998471$ & HRH4, ZNF521 \\
\hline & rs134105133-rs133615999 & 161 & 2.00 & 13 & $8009711 \ldots 8998026$ & - \\
\hline & rs133460769-rs109902312 & 255 & 1.29 & 9 & $8000493 \ldots 8996276$ & - \\
\hline \multirow[t]{4}{*}{ FCR } & rs110424374-rs133308150 & 73 & 6.06 & 12 & $27042151 \ldots 27967155$ & - \\
\hline & rs41942246-rs134122046 & 191 & 5.99 & 20 & $36002437 \ldots 36994188$ & GDNF \\
\hline & rs42594525-rs109404921 & 182 & 1.52 & 15 & $58000208 \ldots 58999275$ & LIN7C \\
\hline & rs109105703 -rs136356118 & 189 & 1.40 & 18 & $15002281 \ldots 15989210$ & - \\
\hline \multirow[t]{4}{*}{$\mathrm{FE}$} & rs133645581-rs137479730 & 231 & 2.58 & 9 & $22019753 \ldots 22993318$ & - \\
\hline & rs134914044-rs42277860 & 203 & 2.30 & 1 & $21002744 \ldots 21985704$ & - \\
\hline & rs136028559-rs1 10570158 & 250 & 1.04 & 14 & $73002666 \ldots 73999191$ & - \\
\hline & rs109171156-rs42987702 & 255 & 1.03 & 2 & $58005318 \ldots 58996319$ & - \\
\hline \multirow[t]{4}{*}{ RFI } & rs132846819-rs136767848 & 217 & 1.50 & 8 & $43001055 \ldots 43994362$ & \\
\hline & rs109535395-rs134508640 & 50 & 1.42 & 18 & $14008775 \ldots 14999189$ & DEPP1, TUBB3 \\
\hline & rs109365529-rs132654030 & 186 & 1.12 & 11 & $93000777 \ldots 93986308$ & PTGS1 \\
\hline & rs136295413-rs41980878 & 260 & 1.12 & 21 & $35004352 \ldots 35999673$ & - \\
\hline \multirow[t]{6}{*}{ ME } & rs110886051-rs136158385 & 132 & 2.23 & 9 & $85000924 \ldots 85992426$ & - \\
\hline & rs135793109-rs134017120 & 244 & 1.48 & 14 & $83000515 \ldots 83999590$ & - \\
\hline & rs132642498-rs42290512 & 195 & 1.28 & 20 & $42002534 \ldots 42999156$ & - \\
\hline & rs136695261-rs134921622 & 265 & 1.24 & 1 & $155006277 \ldots 155998842$ & $\mathrm{DPH} 3$ \\
\hline & rs41681891-rs111007160 & 315 & 1.22 & 13 & $19000011 \ldots 19998017$ & - \\
\hline & rs134217291-rs43586239 & 245 & 1.11 & 1 & $156005880 \ldots 156999077$ & - \\
\hline \multirow[t]{5}{*}{$\mathrm{EG}$} & rs135733781-rs136250718 & 170 & 3.42 & 10 & $82000451 \ldots 82991463$ & - \\
\hline & rs41681891-rs111007160 & 315 & 2.01 & 13 & $19000011 \ldots 19998017$ & - \\
\hline & rs135553767-rs133216097 & 265 & 1.73 & 20 & $58002823 \ldots 58996938$ & - \\
\hline & rs132642498-rs42290512 & 195 & 1.39 & 20 & $42002534 \ldots 42999156$ & - \\
\hline & rs134907990-rs135714341 & 143 & 1.14 & 28 & $29001640 \ldots 29996795$ & CAMK2G \\
\hline \multirow[t]{6}{*}{ PEG } & rs135793109- rs134017120 & 244 & 2.25 & 14 & $83000515 \ldots 83999590$ & - \\
\hline & rs136639955- rs109263205 & 208 & 1.63 & 10 & $27001939 \ldots 27998826$ & - \\
\hline & rs41681891 -rs111007160 & 315 & 1.30 & 13 & $19000011 \ldots 19998017$ & - \\
\hline & rs42442541-rs42102604 & 324 & 1.29 & 26 & $46000238 \ldots 46999583$ & ADAM12 \\
\hline & rs137164093 -rs137788588 & 158 & 1.10 & 3 & $55053110 \ldots 55996246$ & - \\
\hline & rs43109937-rs135732317 & 102 & 1.08 & 1 & $18002981 \ldots 18998146$ & $C X A D R$ \\
\hline \multirow[t]{4}{*}{ RGR } & rs110498934...rs109401708 & 89 & 9.07 & 2 & $63002463 \ldots 63957289$ & - \\
\hline & rs135507221 ...rs136312022 & 170 & 1.72 & 12 & $64002872 \ldots 64983441$ & - \\
\hline & rs41576182.. rs137330342 & 227 & 1.23 & 12 & $63000336 \ldots 63998631$ & - \\
\hline & rs137740719 ...rs132674185 & 236 & 1 & 9 & $75004071 \ldots 75998811$ & MAP7, PEX7 \\
\hline
\end{tabular}


(ZNF804B), characterized by coordination and stabilization of zinc ions in several ionic exchange processes associated to DMI in Nelore cattle on BTA4 [10].

Six genomic regions explained $>1 \%$ of genetic variance for ADG (Table 3). The region on BTA9 at $22 \mathrm{Mb}$ was also associated with FE. On BTA7 at $28 \mathrm{Mb}$ two genes with biological function related to weight gain have been annotated; membrane-associated ring finger $(M A R C H 3)$ and aldehyde dehydrogenase 7 family, member A1 (ALDH7A1). $M A R C H 3$ gene is related to proteolysis according to gene ontology terms (GO: 0006508). Proteolysis is the hydrolysis of proteins into smaller polypeptides and/or amino acids by cleavage of their peptide bonds (Kegg). A study have indicated that rates of proteolysis and protein synthesis are greater in obese than in lean subjects, whereas others studies have not supported this findings [29]. ALDH7A1 gene is part of a pathway related to glycolysis/gluconeogenesis (Kegg). Glycolysis is the sequence of reactions that metabolizes one molecule of glucose to two molecules of pyruvate with the concomitant production of ATP [30], and the glycolytic/gluconeogenic pathways may play an integral role in body weight regulation [31]. ALDH7A1 gene encodes the antiquin protein that has been shown to be associated with increased body weight gain and obesity in rats [32].

On BTA3 at $8 \mathrm{Mb}$ three candidate genes were identified; apolipoprotein A-II (APOA2), ubiquitin specific peptidase 21 (USP21), and ubiquitin-fold modifier conjugating enzyme 1 (UFC1). APOA2 gene has been assigned biological terms of protein transport (GO: 0051223), lipid metabolism (GO: 0008610) and response to carbohydrate stimulus (GO: 0009743). APOA2 gene produces apolipoprotein AII that is a key regulatory factor of HDL metabolism [33]. Polymorphisms in this gene has been reported to be associated with obesity and body weight in humans [34], and Fontanesi et al. [35] proposed APOA2 as a candidate gene for back fat thickness in pigs. The genes USP21 and UFC1 are related to proteolysis gene ontology terms, and are members of Ubiquitin family gene. The ubiquitin system regulates virtually all aspects of cellular function [36], from regulation of gene expression to processes related to reticulum associated degradation of proteins, lysosomal degradation, protein degradation via the proteasome, cell signaling and DNA repair [37]. These processes are generally described as post-translational regulation of gene expression and may cause variation in phenotypes by influencing the levels of proteins and their activity in performing the biochemical processes [38]. Karisa et al. [38] identified a hub of $U B C$ [ubiquitin C] associated with RFI in Bos taurus.

For FCR, four genomic regions explained $>1 \%$ genetic variance (Table 3 ). The region on BTA18 at $15 \mathrm{Mb}$ was also associated with FE (Additional file 1: Table S1). One functional candidate gene was selected within the genomic region on BTA15 at $58 \mathrm{Mb}$; lin7 homolog c (LIN7C). This gene has been assigned gene ontology terms associated with protein transport and localization (GO: 0008104). LIN7C gene plays has a hole on type- 2 diabetes primarily through modulation of adiposity, and Maggie et al. [39] analyzed genetic variants in LIN7C related with obesity and type- 2 diabetes in humans. The glial cell line-derived neurotrophic factor (GDNF) is annotated in the $36 \mathrm{Mb}$ genomic region on BTA20. The protein encoded by this gene has been described as secreted from adipose cells [40]. The adipocytes secrete hormones with an important role in fat deposition and obesity [41]. The gene ontology terms associated to it are muscle system process (GO: 0003012) and positive regulation of nitrogen compounding metabolic process (GO: 0051173).

Four genomic regions explained $>1 \%$ of genotypic variance for FE (Table 3).

Four genomic regions explained $>1 \%$ of genetic variance for RFI (Table 3). The region on BTA18 at $14 \mathrm{Mb}$ is between two regions that each explained more than $0.5 \%$ of genetic variance for other feed efficiency traits (FCR and FE, Additional file 1: Table S1). Two positional candidate genes related to proteolysis gene ontology terms (GO: 0006508; GO: 0006461) were selected in this region; dipeptidase 1 (DEPP1) and tubulin beta 3 (TUBB3). According to Richardson et al. [42] the protein degradation and protein turnover contribute to variation on RFI, and genes involved in these processes are good candidates for improving feed efficiency [43]. The associated region on BTA11 at $93 \mathrm{Mb}$ harbors the prostaglandin-endoperoxide synthase 1 (PTGS1). PTGS1 gene is involved with fatty acid metabolic process (GO: 0006631) and lipid biosynthetic (GO: 0008610). PTGS1 is a key enzyme in prostaglandin biosynthesis, which are produced in different life stages of adipocytes [44]. Adipocyte differentiation and adipogenesis are important in terms of obesity and related to diabetes in mammalians [45].

Six $1 \mathrm{Mb}$ genomic regions explained $>1 \%$ of genetic variance for $\mathrm{ME}$ (Table 3). In addition to being associated with maintenance efficiency, two adjacent regions on BTA1, at 155 and $156 \mathrm{Mb}$, were also associated for ADG (Additional file 1: Table S1). A single gene that is associated to mouse development [46] was selected in this region; $\mathrm{S}$. cerevisae, homolog (DPH3). The translation elongation factor 2 in eukaryotes (eEF-2) contains a unique posttranslational modified histidine residue, termed diphthamide [46]. $D P H 3$ is a small protein required for diphthamide biosynthesis and plays a role in eukaryotic protein complexes that is involved in multiple biological processes [47]. This gene has been assigned gene ontology terms associated with regulation of protein secretion (GO: 0050708) and transport (GO: 0051223). Five genomic regions explained $>1 \%$ of genetic variance for EG (Table 3). The windows on BTA13 at $19 \mathrm{Mb}$ and BTA20 at $42 \mathrm{Mb}$ overlapped with 
regions associated with ME. The SNP window on BTA28 at $29 \mathrm{Mb}$ harbors one gene with function related to calcium metabolism; calcium/calmodulin-dependent protein kinase II gamma (CAMK2G). Studies have implicated $\mathrm{Ca}^{2+}$ as a regulator of a variety of cellular functions, including cell cycle progression and proliferation, fertilization and early development [48]. CAMK2G gene has been implicated in the regulation of other biological processes, such as osteogenic differentiation and maintenance of vascular tone [48]. The CAMK2G is related to with cell cycle (GO: 0022402) and protein amino acid phosphorylation (GO: 0006468) gene ontology terms. Six genomic regions explained $>1 \%$ of genetic variance for PEG (Table 3). The regions on BTA13 at $19 \mathrm{Mb}$ and BTA14 at $83 \mathrm{Mb}$ overlapped with regions for ME. One functional candidate gene have been selected in the window on BTA1 at $18 \mathrm{Mb}$; coxsackie virus and adenovirus receptor (CXADR). CXADR has been assigned gene ontology terms related to muscle organ development (GO: 0007517), regulation of organ growth (GO: 0046620), muscle tissue development (GO: 0060537) and regulation of developmental growth (GO: 0048638). Variants in $C X A D R$ gene were associated with blood pressure and obesity in humans [49]. CXADR plays a role in the electrical conduction of the heart, and it has also been reported to be associated with viral myocarditis and subsequent dilated cardiomyopathy, which is associated with high blood pressure [50]. An interesting gene is annotated on BTA26 at $46 \mathrm{Mb}$; adam metallopeptidase domain 12 (ADAM12). According to Coles et al. [51] $A D A M 12$ is an interesting gene in beef cattle due to its involvement in regulating remodeling of extracellular matrix, modulation of cell morphological changes, satellite cell activation, and ectodomain shedding during signaling of muscle and fat development [52,53]. ADAM12 gene is involved in the regulation of myogenesis and adipogenesis in beef cattle [51]. Kim et al. [54] identified the ADAM12 gene also as a regulator for TGF- $\beta 1$. Transforming growth factor- $\beta 1$ (TGF- $\beta 1$ ) induces the differentiation of human adipose tissue-derived mesenchymal stem cells into smooth muscle cells.

Four genomic regions explained $>1 \%$ of genetic variance for RGR (Table 3). Two genes with function related to skeletal growth have been chosen on BTA9 at $75 \mathrm{Mb}$; microtubule-associated protein 7 (MAP7) and peroxisomal biogenesis factor 7 (PEX7). MAP7 has been assigned biological function related to growth (GO: 0040007), organ growth (GO: 0035265) and cytoskeleton organization (GO: 0007010). Skeletal muscle growth is a complex process [55], since the rate and extent of skeletal muscle growth depends on three factors: muscle protein synthesis; muscle protein degradation; and the number and size of skeletal muscle cells. The metabolic and functional characteristics of skeletal muscles are a result of the biochemical characteristics of the myofibers and the connective tissue matrix
[56]. The basic unit of skeletal muscle in all metazoans is the multinucleate myofiber, within which individual nuclei are regularly positioned. MAP7 gene is an essential regulator of myonuclear positioning required for skeletal muscle function in mammalians [57]. PEX7 has also been assigned gene ontology terms associated to skeletal system development (GO: 0001501) and bone development (GO: 0060348). This gene was related to skeleton development in mouse [58].

The QTL regions described in this study harbor genes with biological functions related to immune and inflammatory responses, ionic and calcium metabolism, proteolysis, lipid and fatty acid metabolism, glycolysis, ubiquitin system, generation of energy, growth and development. Barendse et al. [23] in a study that utilized Bos taurus and Bos indicus steers reported 141 genetic regions associated with RFI. The described genes had biological functions also related to growth and development, immune and inflammation, protein turnover, ion channels and DNA binding proteins, fatty acid metabolism, ubiquitin system, and others additional process like transcription and translation, apoptosis, subcellular organelles, signal transduction and leptin signaling. Rolf et al. [22] in a GWAS for feed efficiency in Angus cattle also reported genes related to metabolic processes for growth and efficiency of energy utilization, such as cell growth and death, metabolic disorders and signal transduction. In a study with Nelore steers, Bonilha et al. [17] reported other physiological processes with an important role in feed efficiency; digestibility, feeding pattern, heat production, physical activity, stress, composition of gain and ruminal metabolism. Santana et al. [10] in recent GWAS for RFI and DMI with Nelore cattle found genes related to ionic transport, ionic exchange processes and leptin signaling. These results indicate that several physiological mechanisms maybe behind feed intake control in beef cattle. Although no functional experiment was done to support the implication of these genes on the phenotypes, these are the best candidates based on the methodology used to indicate genes within QTL regions.

Some genomic regions overlapped between the traits analyzed in this study. Regions on BTA9 overlapped between seven different efficiency traits; DMI, ADG, FE, ME, RGR, EG and PEG (Table 3, Additional file 1: Table S1). One region on BTA9 at $22 \mathrm{Mb}$ overlapped between FE and ADG; and the other region at $85 \mathrm{Mb}$ overlapped between FE, GE and ME. This chromosome harbors QTLs described for body weight in Angus cattle [59] and residual feed intake in Angus and Charolais cattle [24].

The BTA 1, 13, 14, 18 and 24 also contained regions that overlapped between the traits analyzed (Table 3, Additional file 1: Table S1). Two regions on BTA1 overlapped between ADG, ME and GE $156 \mathrm{Mb}$; and between PEG, ME and EG $180 \mathrm{Mb}$. The BTA1 has previously QTL described for body weight and feed conversion ratio in Bos taurus [59]. 
A single region on BTA13 $19 \mathrm{Mb}$ overlapped between ME, GE and PEG. The BTA13 has previously QTL described for carcass weight and body weight [59] in Angus and Charolais cattle [8].

On BTA14, one region at $83 \mathrm{Mb}$ overlapped between 5 traits: FE, FCR, ME, EG and PEG. The BTA14 harbor already described QTL for body weight in Brangus cattle [60] and subcutaneous fat in Canchim cattle [61]. Other studies found SNPs associated with DMI in the BTA14 in beef cattle [22,62] and pigs [63].

For BTA18, the $15 \mathrm{Mb}$ region overlapped between FCR and FE. This chromosome harbor QTL described for carcass weight in Bos indicus x Bos taurus cattle [64] and fat thickness in Angus cattle [59]. On BTA24, the $32 \mathrm{Mb}$ region overlapped between two traits, DMI and RFI. The BTA24 has previously QTL described fat thickness for Bos taurus cattle [59]. These overlapped regions on BTA 1, 9, 13, 14, 18 and 24 seems to be important QTL regions for feed efficiency traits in this study.

The genomic regions controlling dry matter intake and residual feed intake in this study are somehow different from those in previous work. Santana et al. [10] found the BTA 4, 8, 14 and 21 associated to DMI and RFI in Nelore cattle. In this study, regions on BTA 9, 13 and 24, and on BTA 8, 11, 18 and 21 were identified for DMI and RFI, respectively. Only BTA 8 and 21 had a RFI QTL in both studies. These differences can be partially explained by differences in the experimental design and genetic basis of populations. Some of the discrepancies observed could be the result of hormonal environment effects on genes or QTLs, since in Santana et al. [10] both young bulls and steers were used, whereas in the present work there were only steers. Regarding to genetic basis, unrelatedness among sires of the different studies could lead to the differences observed.

Feed efficiency is a polygenic trait [9] characterized by complex interactions between cellular constituents (DNA, RNA) and proteins, influenced by multiple biological process [38]. Our results indicate several QTLs and genes control feed efficiency traits in Nelore cattle. Some QTL regions (BTA 3, 10, 11, 15, 20, 28) and some functional candidate genes identified have not been reported in public databases for feed efficiency traits in Bos taurus cattle, which indicates that feed efficiency in this Nelore population maybe is controlled by some specific regions. Discrepancies of SNP allele frequencies or the extent of linkage disequilibrium (LD]) of markers between taurine and indicine cattle could result in different marker effects being detected in different breeds [65]. Also, the relatively modest size of the population employed in this study may influence the results, and more studies with more Nelore populations will be required to validate this results.

According to Barendse et al. [23] genes affecting a particular trait will change in different species, and breed differences in performance and efficiency are well established [8]. Despite some difference between genes and genomic regions found in this study for Bos indicus, the physiological and metabolic processes of immune and inflammatory responses, ionic and calcium metabolism, proteolysis, glycolysis, lipid and fatty acid metabolism, ubiquitin system, generation of energy, growth and development related to feed efficiency seems to be similar between the two subspecies [10,22,23,25].

The studies of genomic regions and candidate genes associated with production traits paves the way to understanding the possible biological processes related to these traits, and most of these physiological mechanisms are still unclear. GWAS of complex traits for Nelore cattle breed is now emerging and they are important since has a little research reporting regions and genes associated to feed efficiency traits in this breed.

\section{Conclusions}

Besides some previously reported genomic regions associated to feed efficiency in Bos taurus, the present genome wide association study identified several novel genomic regions, which indicates that feed efficiency is controlled by some specific regions in this Nelore population. Genes within these regions could be candidate genes for feed efficiency traits in Nelore cattle.

Once the genes and/or genomic segments that control feed efficiency related traits have been identified it should be possible to determine the biological mechanisms and the genetic basis underlying these traits. Thus, further studies with other Nelore population to validate this results will be required in order to implement selection for this trait in Nelore breeding programs in Brazil.

Since feeding is the main component of cattle production costs and Nelore is the breed of greatest economic importance in Brazil, the ability to identify and select for feed efficient animals should have a considerable economic impact. Development of molecular criteria for improving feed efficiency in Nelore should also contribute to reductions in the environmental impact of beef production in the tropics.

\section{Methods}

Animals were handled and managed according to Institutional Animal Care and Use Committee Guidelines (Brazilian Agricultural Research Corporation - EMBRAPA, Brazil).

\section{Animals and phenotypic data}

A total of 593 Nelore steers with average of $382.5 \mathrm{~kg}$, offspring's of 34 sires were used in this study. Sires were chosen to represent the main genealogies based on the information of the principal summaries of Brazilian Associations and to represent the average price of semen in use by Brazilian beef cattle farmers. Half-sib families 
were produced by artificial insemination of commercial and purebred Nelore dams. The range of the number of offspring per sire was 2 to 20. Calves were born on three different ranches, where they were raised to around 21 months old, before allocation to individual or collective pens where individual feed intake data were measured in a feedlot located in São Carlos, SP, Brazil; or in Campo Grande, MS, Brazil.

Animals were fed ad libitum twice daily, with refusals of $5 \%$ discarded daily. Diets contained 40\% dry matter (DM) in the form of corn silage (trial 1) or sorghum silage (trial 2 ); crude protein at $13.5 \%$ (trial 1), $15.4 \%$ (trial 2); energy densities of 2.8 (trial 1) or $2.6 \mathrm{Mcal}$ metabolizable energy per $\mathrm{kg}$ DM (trial 2), 60\% DM of concentrate, which contained ground corn, soybean meal, cotton seed (only trial 1 ), soybean grain (only trial 2), soybean hull, limestone, mineral mixture, urea and monensin (Rumensin ${ }^{\circ}$ ). The adaptation period was approximately 28 days and individual dry matter intake (DMI) was measured for at least 70 days with non-fasted body weight (BW) measured every 14 days.

Individual dry matter intake (DMI, $\mathrm{kg} / \mathrm{d}$ ) was obtained by the difference between offer and refusal and average daily gain (ADG, kg/d) was estimated by regression of body weight $(\mathrm{BW})$ on days on feed using PROC REG (SAS, 2010). Feed conversion ratio (FCR, $\mathrm{kg} / \mathrm{kg}$ ) was computed as the ratio of DMI to ADG $(\mathrm{kg} / \mathrm{d})$, where the inverse of this ratio was represented by feed efficiency (FE, $\mathrm{kg} / \mathrm{kg}$ ). Residual feed intake (RFI, kg/d) was computed as the residuals from regression of DMI on midtest $\mathrm{BW}^{0.75}$ and $\mathrm{ADG}$ [2] using mixed models, where contemporary group (CG) was defined as feedlot location, year, animal origin and pen type (individual or collective), which were considered fixed effects by MIXED procedure (SAS, 2010). The partial efficiency of growth (PEG, $\mathrm{kg} / \mathrm{kg}$ ) that represents the energetic efficiency for ADG above maintenance was computed as the ratio of ADG to the difference between average daily DMI and expected DMI for maintenance (DMIm), where DMIm was computed using the NRC 1996 maintenance requirement equations and Zinn and Shen [66] equations to estimate net energy of the diet for maintenance. The efficiency of gain (EG, kg/Mcal) was obtained by dividing ADG by metabolizable energy intake (Mcal/d). To calculate the relative growth rate $(\mathrm{RGR}, \% / \mathrm{d})$ the equation was: $\mathrm{RGR}=100 *\left(\log \mathrm{BW}_{\text {final }}-\log \mathrm{BW}\right.$ initial $) /$ days of experiment [5]. The total number of animals $(\mathrm{N})$ used for GWAS was slightly different between traits because of different availability of data.

\section{DNA extraction and genotypic data}

Genomic DNA was extracted from blood samples [65]. Genotyping was performed at the United States Department of Agriculture Laboratory of Functional Genomics (ARS/ USDA) with the BovineHD BeadChip, $770 \mathrm{~K}$ (Illumina,
San Diego, CA). Genome Studio Data Analysis software (Illumina) was used to visualize SNP data and to perform initial analyses. The genotypes were recorded in Illumina $\mathrm{A} / \mathrm{B}$ allele format and transformed to a value of 0,1 , or 2 , representing the number of $\mathrm{B}$ alleles present. Missing genotypes represented less than $0.2 \%$ of total observations and were replaced with the average number of B alleles for that locus. SNPs with call rate $\geq 95 \%$ and minor allele frequency $(\mathrm{MAF}) \geq 5 \%$ were used in the analyses. SNPs in sex chromosomes and not mapped in the Bos taurus UMD 3.1 assembly were excluded. A total of 449,363 SNP were utilized in this study.

\section{Descriptive statistics}

Descriptive statistics for ADG, DMI, FCR, FE, RFI, ME, EG, PEG and RGR were performed by PROC MEANS of SAS [67]. The PROC UNIVARIATE was used to test and visualize normality of the data, and PROC MIXED used to test significant effects. The fixed effects for contemporary group (CG) included origin, pen type, year and location of feedlot, and age as a covariate, were used in the genomic association model.

\section{Genome wide association study}

Bayesian approaches were developed to avoid false positives and overestimation of QTL effects [60,68-70]. The Bayes C methodology [71-73] was used to estimate the genetic and residual variances for use as priors in Bayes $\mathrm{B}$. The Bayes $\mathrm{C}$ priors assumed genetic and residual variance equal to 1 and $\pi=0.9997$. The GWAS between genotypes and phenotypes (ADG, DMI, FCR, FE, RFI, ME, GE, PEG and RGR) were undertaken with Bayes B, which analyzed all SNP data simultaneously and assumed a different genetic variance for each SNP locus $[18,19,73]$, based on the model equation:

$$
\boldsymbol{y}=\mathbf{X} \boldsymbol{b}+\sum_{j=1}^{K} \boldsymbol{a j} \beta j \delta j+\boldsymbol{e}
$$

where; $\mathbf{y}$ is a vector of phenotypic values, $X$ is an incidence matrix for fixed effects, $\boldsymbol{b}$ is a vector of fixed effects representing contemporary groups, $K$ is the number of SNP loci $(449,363), \boldsymbol{a} j$ is the column vector representing the SNP covariate at locus $j$ coded as the number of $\mathrm{B}$ alleles, $\beta j$ is the random substitution effect for locus $j$, which conditional on $\sigma_{\beta}^{2}$ was assumed normally distributed $N(0$, $\sigma_{\beta}^{2}$ ) when $\delta j=1$ but $\beta j=0$ when $\delta j=0$, with $\delta j$ being a random $0 / 1$ variable indicating the absence (with probability $\pi$ ) or presence (with probability $1-\pi$ ) of locus $j$ in the model, and $\boldsymbol{e}$ is a vector of random residual effects assumed normally distributed $N\left(0, \sigma_{e}^{2}\right)$. The variance $\sigma_{\beta}^{2}$ (or $\sigma_{e}^{2}$ ) was a priori assumed to follow a scaled inverse Chisquare with $v \beta=4$ (or $v e=10$ ) degrees of freedom and scale parameter $S_{\beta}^{2}$ (or $S_{e}^{2}$ ). The scale parameter for markers 
was derived as a function of the assumed known genetic variance of the population, based on the average SNP allele frequency and number of SNP assumed to have nonzero effects, based on $\pi=0.9997$. The parameter $\pi$ was 0.9997 chosen to fit fewer markers than animals. The GWAS was conducted with GenSel software [74], which uses MCMC methods to calculate posterior mean estimates of marker effects and variances.

The chains included 41,000 iterations with first 1,000 samples used for burn-in [19]. Markers effects from every 40th post burn-in iteration were used to characterize genomic merit for each animal for every $1 \mathrm{Mb}$ window. In the Bayesian variable selection multiple-regression models with $\pi=0.9997$ about 100-150 SNP markers were fitted simultaneously in each MCMC iteration. Inference of associations in these multiple-regression models was based on 1-Mb genomic windows rather than on single markers $[68,69]$. Genomic windows were constructed based on the chromosome and base pair positions denoted in a marker map file based on UMD-3.1 [68].

The SNP effects from every 40th post burn in iteration were used to obtain samples from the posterior distribution of the proportion of variance accounted for by each window from 1,000 MCMC samples of genomic merit for each animal following Onteru et al. [69] and Peters et al. [70]. In this study 2,527 SNP windows were used across the 29 chromosomes. The proportion of genetic variance explained by each window in any particular iteration was obtained by dividing the variance of the breeding values for the window by the variance of breeding value for whole genome in that iteration. Window genetic variance was computed by multiplying the number of alleles that represent the SNP covariates for each consecutive SNP in a window by their respective posterior means for substitution effects. The SNP windows that explained $>1 \%$ of genetic variance from Bayes B analysis were considered as QTL associated with traits [60]. SNP windows that explained 0.5 to $1 \%$ of genetic variance are present as additional information in the supplemental material. The UMD-3.1 bovine assembly in Animal QTL database (http://www.animalgenome.org/QTLdb) and the Bovine QTL database (https:// genome.ucsc.edu/) were used to search for QTLs previously described in the literature. Positional candidate genes were selected in $1 \mathrm{Mb}$ windows that explained $>1 \%$ of genetic variance [60] based on physiological and metabolic function. DAVID [75] and GO [37] were used to ascribe the functional classification of genes. No pathway analysis was conducted. Genes with biological function related to the trait and with support on literature were defined as positional and functional candidate genes.

\section{Availability of supporting data}

The data set supporting the results of this article is included within the article (and its additional files). Genotypic data is available upon request depending on a signed declaration of exclusive research purpose.

\section{Additional files}

\author{
Additional file 1: QTL regions associated with feed efficiency traits \\ in Nelore cattle. \\ Additional file 2: Manhattan plots of QTL regions associated with \\ dry matter intake in Nelore cattle. \\ Additional file 3: Manhattan plots of QTL regions associated with \\ average daily gain in Nelore cattle. \\ Additional file 4: Manhattan plots of QTL regions associated with \\ feed conversion ratio in Nelore cattle. \\ Additional file 5: Manhattan plots of QTL regions associated with \\ feed efficiency in Nelore cattle. \\ Additional file 6: Manhattan plots of QTL regions associated with \\ residual feed intake in Nelore cattle. \\ Additional file 7: Manhattan plots of QTL regions associated with \\ maintenance efficiency in Nelore cattle. \\ Additional file 8: Manhattan plots of QTL regions associated with \\ partial efficiency of grow in Nelore cattle. \\ Additional file 9: Manhattan plots of QTL regions associated with \\ efficiency of gain in Nelore cattle. \\ Additional file 10: Manhattan plots of QTL regions associated with \\ relative growth rate in Nelore cattle.
}

\section{Abbreviations}

ADG: Average daily gain; BW: Body weight; DM: Dry matter; DMI: Dry matter intake; DMIm: Dry matter intake for maintenance; EG: Efficiency of gain; FCR: Feed-conversion ratio; FE: Feed efficiency; GWAS: Genome wide association study; ME: Maintenance efficiency; PEG: Partial efficiency of growth; RGR: Relative growth rate; RFI: Residual feed intake.

\section{Competing interests}

The authors declare that they have no competing interests.

\section{Authors' contributions}

PSNO and LCAR: conception and design of research; PSNO, PCT, LCAR and TSS: performed experiments; PSNO, MLN, ASC, DPL, RRT, ANR: collected samples and phenotypes; PSNO, ASMC, GBM, LLC, MAM, JMR and DJG analyzed the data; PSNO and ASMC: prepare figures, PSNO, ASMC, JMR, DJG and LCAR interpreted the results of experiments; PSNO, ASMC, JMR and LCAR drafted the manuscript, PSNO, ASMC, PCT, JMR and LCAR revised the manuscript. All authors read and approved the final manuscript.

\section{Acknowledgments}

This work was supported by CNPq, National Council for Scientific and Technological Development - Brazil. We thank Flávia Aline Bressani and Wilson M. Júnior for technical assistance; Embrapa Southeast-Cattle Research Center [Brazil], São Carlos Federal University [Brazil], lowa State University [USA], USDA ARS Bovine Functional Genomics Laboratory [USA]; the CNPq for providing financing and fellowship to Lanna, D.P, Mourão G. B, Coutinho, L.L. and Regitano, L. C. A; and CAPES and CNPq for providing a scholarship to Priscila Silva Neubern de Oliveira.

\section{Author details}

'Department of Genetics and Evolution, Federal University of Sao Carlos, 13565-905 Sao Carlos, SP, Brazil. 'Department of Animal Science, University of Sao Paulo, 13418-900 Piracicaba, SP, Brazil. ${ }^{3}$ Embrapa Southeast-Cattle Research Center, 13560-970 Sao Carlos, SP, Brazil. ${ }^{4}$ Embrapa Beef Cattle, 79002-970 Campo Grande, MS, Brazil. ${ }^{5}$ USDA ARS Bovine Functional Genomics Laboratory, Beltsville, MD 20705, USA. ${ }^{6}$ Department of Animal Science, lowa State University, Ames, IA 50011, USA.

Received: 6 December 2013 Accepted: 10 September 2014 Published online: 26 September 2014 


\section{References}

1. Basarab JA, Price MA, Aalhus UL, Okine EK, Snelling WM, Lyle KL: Residual feed intake and body composition in young growing cattle. J Anim Sci 2003, 83:189-204.

2. Koch RM, Swinger LA, Chambers D, Gregory KE: Efficiency of feed use in beef cattle. J Anim Sci 1963, 22:486-494.

3. Archer JA, Richardson EC, Herd RM, Arthur PF: Potential for selection to improve efficiency of feed use in beef cattle: a review. J Agric Res 1999, 50:147-161

4. Kellner O: The Scientific Feeding Of Animals. New York: McMillan; 1909.

5. Fitzhugh HA, Taylor CS: Genetic analysis of degree of maturity. J Anim Sci 1971, 33:717-725.

6. Arthur PF, Archer JA, Johnston DJ, Herd RM, Richardson EC, Parnell PF: Genetic and phenotypic variance and covariance components for feed intake, feed efficiency, and other postweaning traits in Angus cattle. J Anim Sci 2001, 79:2805-2811.

7. Sherman EL, Nkrumah JD, Moore SS: Whole genome single nucleotide polymorphism associations with feed intake and feed efficiency in beef cattle. J Anim Sci 2010, 88(1):16-22. doi:10.2527/jas.2008-1759.

8. Nkrumah JD, Basarab JA, Wang Z, Li C, Price MA, Okine EK, Crews DH Jr, Moore SS: Genetic and phenotypic relationships of feed intake and measures of efficiency with growth and carcass merit of beef cattle. J Anim Sci 2007, 85:2711-2720.

9. Bolormaa S, Pryce JE, Kemper K, Savin K, Hayes BJ, Barendse W, Zhang Y, Reich CM, Mason BA, Bunch RJ, Harrison BE, Reverter A, Herd RM, Tier B, Graser H-U, Goddard ME: Accuracy of prediction of genomic breeding values for residual feed intake, carcass and meat quality traits in Bos taurus, Bos indicus and composite beef cattle. J Anim Sci 2013, 91(7):3088-3104

10. Santana MHA, Utsunomiya YT, Neves HHR, Gomes RC, Garcia JF, Fukumasu H, Ferraz JBS: Genome-wide association analysis of feed intake and residual feed intake in Nellore cattle. BMC Genet 2014. doi:10.1186/1471-2156-15-21.

11. Fortes MRS, Snelling WM, Reverter A, Nagaraji SH, Lehnert SA, Hawken RJ, DeAtley KL, Peters SO, Silver GA, Rincon G, Medrano JF, Isla-Trejo A, Thomas MG: Gene network analyses of first service conception in Brangus heifers: Use of genome and trait associations, hypo-thalamic-transcriptome information, and transcription factors. J Anim Sci 2012, 90:2894-2906.

12. Snelling WM, Cushman RA, Fortes MRS, Reverter A, Bennett GL, Keele JW, Kuehn LA, McDaneld TG, Thallman RM, Thomas MG: How SNP chips will advance our knowledge of factors controlling puberty and aid in selecting replacement females. J Anim Sci 2012, 90:1152-1165.

13. Nkrumah JD, Basarab JA, Price MA, Okine EK, Ammoura A, Guercio S, Hansen C, Li C, Benkel B, Moore SS: Different measures of energetic efficiency and their relationships with growth, feed intake, ultrasound and carcass measurementsin hybrid cattle. J Anim Sci 2004, 82:2451-2459.

14. Elzo MA, Riley DG, Hansen GR, Johnson DD, Myer RO, Coleman SW, Chase CC, Wasdin JG, Driver JD: Effect of breed composition on phenotypic residual feed intake and growth in Angus, Brahman, and Angus $x$ Brahman crossbred cattle. J Anim Sci 2009, 87:3877-3886.

15. Crowley JJ, Evans RD, Mc Hugh N, Kenny DA, McGee M, Crews D Jr, Berry DP: Genetic relationships between feed efficiency in growing males and beef cow performance. J Anim Sci 2010, 89:3372-3381

16. Corvino TLS, Branco RH, Bonilha SFM, Castilhos AM, Figueiredo LA, Razook AG, Mercadante MEZ: Residual feed intake and relationships with performance of Nelore cattle selected for post weaning weight. Rev Bras Zootec 2011, 40:929-937.

17. Bonilha EFM, Branco RH, Bonilha SFM, Araujo FL, Magnani E, Mercadante MEZ: Body chemical composition of Nelore bulls with different residual feed intakes. J Anim Sci 2013, 91(7):3457-3464

18. Meuwissen THE, Hayes BJ, Goddard ME: Prediction of total genetic value using genome-wide dense marker maps. Genetics 2001, 157:1819-1829.

19. Saatchi M, Ward J, Garrick DJ: Accuracies of direct genomic breeding values in Hereford beef cattle using national or international training populations. J Anim Sci 2013, 91(4):1538-1551.

20. Bolormaa S, Hayes BJ, Hawken RJ, Zhang Y, Reverter A, Goddard ME: Detection of chromosome segments of zebu and taurin origin and their effect on beef production and growth. J Anim Sci 2011, 89:2050-2060.

21. Elzo MA, Lamb GC, Johnson DD, Thomas MG, Misztal I, Rae DO, Martinez CA, Wasdin JG, Driver JD: Genomic-polygenic evaluation of AngusBrahman multibreed cattle for feed efficiency and postweaning growth using the Illumina 3 K chip. J Anim Sci 2012, 90:2488-2497.

22. Rolf MM, Taylor JF, Schnabel RD, Mckay SD, McClure MC, Northcutt SL, Kerley MS, Weaber RL: Genome-wide association analysis for feed efficiency in Angus cattle. Anim Genet 2011, 43:367-374.

23. Barendse W, Reverter A, Bunch RJ, Harrison BE, Barris W, Thomas MB: A validated whole-genome association study of efficient food conversion in cattle. Genetics 2007, 176:1893-1905.

24. Sherman EL, Nkrumah JD, Li C, Bartusiak R, Murdoch B, Moore SS: Fine mapping quantitative trait loci for feed intake and feed efficiency in beef cattle. J Anim Sci 2009, 87(1):37-45.

25. Karisa BK, Thomson J, Wang Z, Stothard P, Moore SS, Plastow GS: Candidate genes and single nucleotide polymorphisms associated with variation in residual feed intake in beef cattle. J Anim Sci 2013, 91(8):3502-3513.

26. Jones BL, Kearns GL: Histamine: new thoughts about a familia mediator. Clin Pharmacol Ther 2011, 89:189-197.

27. Rangachari PK: Histamine: mercurial messenger in the gut. Am J PhysiolGastrointest Liver Physiol 1992, 262:G1-G13.

28. Ji Y, Sakata Y, Li X, Zhang C, Yang Q, Xu M, Wollin A, Langhans W, Tso P: Lymphatic diamine oxidase secretion stimulated by fat absorption is linked with histamine release. Am J Physiol Gastrointest Liver Physiol 2013, 304(8):G732-G740

29. Welle S, Barnard RR, Statt M, Amatruda JM: Increased protein turnover in obese women. Metabolism 1992, 41(9):1028-1034.

30. Berg JM, Tymoczko JL, Stryer L: Biochemistry. 5th edition. New York: W H Freeman; 2002. ISBN-10: 0-7167-3051-0.

31. Visinoni $\mathrm{S}$, Khalid NF, Joannides $C N$ : The role of liver fructose-1,6-bisphosphatase in regulating appetite and adiposity. Diabetes 2012, 61:1122-1132.

32. Joo Jl, Oh TS, Kim DH, Choi DK, Wang X, Choi JW, Yun JW: Differential expression of adipose tissue proteins between obesity-susceptible and -resistant rats fed a high-fat diet. Proteomics 2011, 11:1-20.

33. Kalopissis AD, Pastier D, Chambaz J: Apolipoprotein A-II: Beyond genetic associations with lipid disorders and insulin resistance. Curr Opin Lipidol 2003, 14:165-172.

34. Corella D, Tai ES, Sorlí JV, Chew SK, Coltell O, SotosPrieto M, García-Rios A, Estruch R, Ordovas JM: Association between the APOA2 promoter polymorphism and body weight in Mediterranean and Asian populations: Replication of a gene-saturated fat interaction. Int J Obes 2011, 35:666-675.

35. Fontanesi L, Galimberti G, Calò DG, Fronza R, Martelli PL, Scotti E, Colombo M, Schiavo G, Casadio R, Buttazzoni L, Russo V: Identification and association analysis of several hundred single nucleotide poly morphisms within candidate genes for back fat thickness in Italian Large White pigs using a selective genotyping approach.

J Anim Sci 2012, 90:2450-2464

36. Ernst A, Awakumov G, Tong J, Fan $Y$, Zhao Y, Alberts P, Persaud A, Walker JR, Neculai AM, Neculai D, Vorobyov A, Garg P, Beatty L, Chan PK, Juang YC, Landry MC, Yeh C, Zeqiraj E, Karamboulas K, Allali-Hassani A, Vedadi M, Tyers M, Moffat J, Sicheri F, Pelletier L, Durocher D, Raught B, Rotin D, Yang J, Moran MF, et al: A strategy for modulation of enzymes in the ubiquitin system. Science 2013, 1:339(6119):590-595. doi: 10.1126/science.1230161.

37. Ashburner M, Ball CA, Blake JA, Botstein D, Butler H, Cherry MJ, Davis AP, Dolinski K, Dwight SS, Eppig JT, Harris MA, Hill DP, Issel-Tarver L, Kasarskis A, Lewis S, Matese JC, Richardson JE, Ringwald M, Rubin GM, Sherlock G: Gene ontology: tool for the unification of biology. Nat Genet 2000, 25:25-29.

38. Karisa B, Moore S, Plastow G: Analysis of biological networks and biological pathways associated with residual feed intake in beef cattle. Anim Sci J 2013, 374-387. doi:10.1111/asj.12159.

39. Ng MC, Tam CH, So WY, Ho JS, Chan AW, Lee HM, Wang Y, Lam VK, Chan JC, Ma RC: Implication of genetic variants near NEGR1, SEC16B, TMEM18, ETV5/DGKG, GNPDA2, LIN7C/BDNF, MTCH2, BCDIN3D/FAIM2, SH2B1, FTO, MC4R, and KCTD15 with Obesity and Type 2 Diabetes in 7705 Chinese. Clin Endocrinol Metab 2010, 95(5):2418-2425

40. Fradette J, Wolfe D, Goins WF, Huang S, Flanigan RM, Glorioso JC: HSV vector-mediated transduction and GDNF secretion from adipose cells. Gene Ther 2005, 12:48-58.

41. Richard AJ, Stephens JM: Emerging roles of JAK-STAT signaling pathways in adipocytes. Trends Endocrinol Metab 2011, 22:325-332.

42. Richardson EC, Herd RM: Biological basis for variation in residual feed intake in beef cattle. Synthesis of results following divergent selection. Aust J Exp Agric 2002, 44:431-440. 
43. Abo-Ismail M, Kelly M: Identification of single nucleotide polymorphisms in genes involved in digestive and metabolic processes associated with feed efficiency and performance traits in beef. J Anim Sci 2013, 2512-2529. doi:10.2527/jas2012-5756.

44. Hossain MS, Chowdhury AA, Rahman MS, Nishimura K, Jisaka M, Nagaya T: Development of enzyme-linked immunosorbent assay for $\Delta 12-P G J 2 a n d$ its application to the measurement of the endogenous product generated by cultured adipocytes during the maturation phase. Prostaglandins Other Lipid Mediat 2011, 94:73-80.

45. Rahman MS, Syeda PK, Khan F, Nishimura K, Jisaka M, Nagaya T, Shono F, Yokota K: Cultured preadipocytes undergoing stable transfection with cyclooxygenase- 1 in the antisense direction accelerate adipogenesis during the maturation phase of adipocytes. App/ Biochem Biotechnol 2013, 171(1):128-144.

46. Liu S, Wiggins JF, Sreenath T, Kulkarni AB, Ward JM, Leppla S: Dph3, a small protein required for diphthamide biosynthesis, is essential in mouse development. Mol Cell Biol 2006, 26(10):3835-3841.

47. Bär C, Zabel R, Liu S, Stark MJR, Schaffrath R: A versatile partner of eukaryotic protein complexes that is involved in multiple biological processes: Kti11/Dph3. Mol Microbiol 2008, 69(5):1221-1233. doi:10.1111/j.1365-2958.2008.06350.

48. Skelding KA, Rostas JAP, Verrills NM: Controlling the cell cycle: The role of calcium/calmodulin-stimulated protein kinases I and II. Cell Cycle 2011, 10(4):631-639. doi:10.4161/cc.10.4.14798.

49. Shetty PB, Tang $H$, Tayo BO, Morrison AC, Hanis $C L$, Rao DC, Young JH, Fox ER, Boerwinkle E, Cooper RS, Risch NJ, Zhu X: Variants in CXADR and F2RL1 are associated with blood pressure and obesity in African-Americans in regions identified through admixture mapping. J Hypertens 2012, 30(10):1970-1976.

50. Lisewski U, Shi Y, Wrackmeyer U, Fischer R, Chen C, Schirdewan A, Jüttner R, Rathjen F, Poller W, Radke MH, Gotthardt M: The tight junction protein CAR regulates cardiac conduction and cell-cell communication. $J$ Exp Med 2008, 205(10):2369-2379.

51. Coles C, Wadeson J: A disintegrin and metalloprotease-12 is type I myofiber specific in Bos taurus and Bos indicus cattle. J Anim 2014, 1473-1483. doi:10.2527/jas2013-7069.

52. Cao Y, Zhao Z, Gruszczynska-Biegala J, Zolkiewska A: Role of metalloprotease disintegrin ADAM 12 in determination of quiescent reserve cells during myogenic differentiation in vitro. Mol Cell Biol 2003, 23:6725-6738.

53. Kawaguchi N, Sundberg C, Kveiborg M, Moghadaszadeh B, Asmar M, Dietrich N, Thodeti CK, Moller P, Mercurio AM, Albrechtsen R, Wewer U: ADAM12 induces actin cytoskeleton and extracellular matrix reorganization during early adipocyte differentiation by regulating beta1 integrin function. J Cell Sci 2003, 116:3893-3904

54. Kim YM, Kim J, Heo SC, Shin SH, Do EK: Proteomic identification of ADAM12 as a regulator for TGF-b1-induced differentiation of human mesenchymal stem cells to smooth muscle cells. PLoS One 2012, 7(7):e40820.

55. Goll DE, Kleese WC, Szpacenko A: Skeletal Muscle Proteases and Protein Turnover. In Animal Growth Regulation. Edited by Campion DR, Hausman GJ, Martin RJ. New York: Plenum Press; 1989:141-183.

56. Maltin C, Delday M, Sinclair K, Steven J, Sneddon A: Impact of manipulations of myogenesis in utero on the performance of adult skeletal muscle. Reproduction 2001, 122:359-374.

57. Metzger T, Gache V, Xu M, Cadot B, Folker ES, Richardson BE, Baylies MK: MAP and kinesin-dependent nuclear positioning is required for skeletal muscle function. Nature 2012, 484(7392):120-124. doi:10.1038/nature10914.

58. Braverman N, Zhang R, Chen L, Nimmo G, Scheper S, Tran T, Chaudhury R, Moser A, Steinberg S: A Pex7 hypomorphic mouse model for plasmalogen deficiency affecting the lens and skeleton. Mol Genet Metab 2010, 99:408-416.

59. McClure MC, Morsci NS, Schabel RD, Kim JW, Yao P, Rolf MM, McKay SD, Gregg SJ, Chapple RH, Northcutt SL, Taylor JF: A genome scan for quantitative trait loci influencing carcass, post-natal growth and reproductive traits in commercial Angus cattle. Anim Genet 2010, 41:597-607.

60. Peters S, Kizilkaya K: Bayesian genome-wide association analysis of growth and yearling ultrasound measures of carcass traits in Brangus heifers. J Anim Sci 2012, 3398-3409. doi:10.2527/jas2012-4507.

61. Veneroni GB, Meirelles SL, Grossi D, Gasparin G, Ibelli AMG, Tizioto PC, Regitano LCA: Prospecting candidate SNPs for backfat in Canchim beef cattle. Genet Mol Res 2010, 9(4):1997-2003. doi:10.4238/vol9-4gmr788.

62. Pryce JE, Arias J, Bowman PJ, Davis SR, Macdonald KA, Waghorn GC, Wales WJ, Williams YJ, Spelman RJ, Hayes BJ: Accuracy of genomic predictions of residual feed 14 intake and 250 day bodyweight in 15 growing heifers using 625,000 SNP markers. J Dairy Sci 2012, 95:2108-2119.

63. Do DN, Strathe AB, Ostersen T, Jensen J, Mark T, Kadarmideen HN Genome-wide association study reveals genetic architecture of eating behavior in pigs and its implications for humans obesity by comparative mapping. PLoS One 2013, 8(8):e71509.

64. Casas E, Shackelford SD, Keele JW, Koohmaraie M, Smith TPL, Stone RT: Detection of quantitative trait loci for growth and carcass composition in cattle. J Anim Sci 2003, 81:2976-2983.

65. Tizioto PC, Decker JE, Taylor JF, Schnabel RD, Mudadu MA, Silva FL, Regitano LCA: Genome scan for meat quality traits in Nelore beef cattle. Physio Genomics 2013, 45(21):1012-1020. doi:10.1152/physiolgenomics.00066.2013

66. Zinn A, Shen YA: An evaluation of ruminal degradable intake protein and metabolizable amino acid requirements of feedlot calves. J Anim Sci 1998, 76:1280-1289.

67. SAS Institute Inc: Base SAS ${ }^{\oplus} 9.2$ Procedures Guide. Cary, NC: SAS Institute Inc:; 2010.

68. Garrick DJ, Fernando RL: Implementing a QTL detection study [GWAS] using genomic prediction methodology. Methods Mol Biol 2013, 1019:275-298.

69. Onteru SK, Fan B, Nikkila MT, Garrick DJ, Stalder KJ, Rothschild MF: Whole-genome association analyses for lifetime reproductive traits in pig. J Anim Sci 2011, 89:988-995.

70. Peters S, Kizilkaya K: Heritability and Bayesian genome-wide association study of first service conception and pregnancy in Brangus heifers. J Anim 2013, 605-612. doi:10.2527/jas2012-5580.

71. Kizilkaya K, Fernando RL, Garrick DJ: Genomic prediction of simulated multibreed and purebred performance using observed fifty thousand single nucleotide polymorphism genotypes. J Anim Sci 2010, 88:544-551.

72. Habier D, Fernando RL, Kizilkaya K, Garrick DJ: Extension of the Bayesian alphabet for genomic selection. BMC Bioinformatics 2011, 12:186.

73. Cesar AS, Regitano LC, Tullio RR, Lanna DP, Nassu RT, Mudado MA Coutinho LL: Genome-wide association study for intramuscular fat deposition and composition in Nellore cattle. BMC Genet 2014, 15(1):39. doi:10.1186/1471-2156-15-39.

74. Fernando R, Garrick DJ: User Manual For A Portfolio Of Genomic Selection Related Analyses, 2nd Ed. For Version 2.12. In Animal Breeding and Genetics. 2nd edition. Ames, IA: lowa State University; 2009.

75. Huang DW, Sherman BT, Lempicki RA: Bioinformatics enrichment tools: paths toward the comprehensive functional analysis of large gene lists. Nucleic Acids Res 2009, 37:1-13.

doi:10.1186/s12863-014-0100-0

Cite this article as: de Oliveira et al:: Identification of genomic regions associated with feed efficiency in Nelore cattle. BMC Genetics 2014 15:100

\section{Submit your next manuscript to BioMed Central and take full advantage of:}

- Convenient online submission

- Thorough peer review

- No space constraints or color figure charges

- Immediate publication on acceptance

- Inclusion in PubMed, CAS, Scopus and Google Scholar

- Research which is freely available for redistribution 